\title{
Assessing community leadership factor in community capacity building in tourism development: a case study of Shiraz, Iran
}

\begin{abstract}
The main purpose of the study is to assess the level of community leadership for community capacity building in tourism development. Six indicators were used to measure community leadership at the community level in the context of tourism development. Findings show that the level of community leadership as a factor of community capacity building is low. However the level in the old district is higher than the new district of Shiraz. t-test also shows that there is a significant difference between the level of community leadership in local communities in new Shiraz and the old Shiraz.
\end{abstract}

Keyword: Leadership; Tourism; Community capacity building; Local communities 